\title{
PENINGKATAN PENGETAHUAN PERILAKU HIDUP BERSIH DAN SEHAT (PHBS) PADA IBU RUMAH TANGGA DI WILAYAH KOTA TANGERANG
}

\author{
Liana Oktariani, Isna Dewi Aulia dan Ria Setia Sari \\ STIKes YATSI Tangerang, Indonesia \\ Email: oktarianilian@gmail.com, isnaaulia2505@gmail.com dan \\ riasetia233@gmail.com
}

\begin{abstract}
Clean and healthy living behavior (PHBS) is a step that must be taken to achieve an optimal health degree for everyone. Healthy conditions do not automatically occur, but efforts must always be made from being unhealthy to healthy living and creating a healthy environment. This effort must start from instilling a healthy lifestyle in society that must be started and worked on by oneself. This effort is to realize the highest public health status as an investment for the development of productive human resources. For this reason, the provision of counseling related to clean and healthy living behaviors is expected to be an effort to make people aware of the importance of making efforts to make healthy and clean living Behaviors in their daily life as well as providing knowledge on how to make it happen so that people who care about health are created. The purpose of this activity is to increase housewives' knowledge about PHBS in the household realm. The extension method uses a virtual power point presentation using the google meet application. The level of knowledge of housewives about PHBS before being given PHBS counseling with the percentage of moderate knowledge criteria was 13 people (65\%) and the criteria for lack of knowledge were 7 people (35\%). While the percentage after being given counseling, the criteria for good knowledge were 17 people (85\%) and the moderate criteria were 3 people (15\%). This shows that there is an increase in the knowledge of the audience who are housewives between before and after being given PHBS counseling.
\end{abstract}

Keywords: clean healthy behavior; online counseling; housewives

\section{Abstrak}

Perilaku hidup bersih dan sehat (PHBS) merupakan langkah yang harus dilakukan untuk mencapai tingkat kesehatan yang optimal bagi setiap orang. Kondisi sehat tidak terjadi secara otomatis, tetapi upaya harus selalu dilakukan dari menjadi tidak sehat hingga hidup sehat dan menciptakan lingkungan yang sehat. Upaya ini harus dimulai dari menanamkan pola hidup sehat di masyarakat yang harus dimulai dan dilakukan sendiri. Upaya ini untuk mewujudkan status kesehatan masyarakat tertinggi sebagai investasi bagi pengembangan sumber daya manusia yang produktif. Oleh karena itu, pemberian penyuluhan terkait perilaku hidup bersih dan sehat diharapkan dapat menjadi upaya mendorong masyarakat untuk melakukan upaya membuat perilaku hidup sehat dan bersih dalam kesehariannya serta memberikan pengetahuan bagaimana mewujudkannya agar masyarakat yang peduli terhadap kesehatan tercipta. Tujuan dari kegiatan ini adalah untuk meningkatkan pengetahuan ibu rumah tangga tentang PHBS dalam rumah tangga. Metode

$\begin{array}{ll}\text { How to cite: } & \text { Oktariani, Liana., et.al. (2021) Peningkatan Pengetahuan Perilaku Hidup Bersih dan Sehat (PHBS) } \\ & \text { Pada Ibu Rumah Tangga di Wilayah Kota Tangerang, Syntax Idea 3(4). } \\ & \text { http://dx.doi.org/10.36418/syntax-idea.1150 } \\ \text { E-ISSN: } & \text { 2684-883X } \\ \text { Published by: } & \text { Ridwan Institute }\end{array}$


ekstensi menggunakan presentasi power point virtual menggunakan aplikasi google meet. Tingkat pengetahuan ibu rumah tangga tentang PHBS sebelum diberikan phbs konseling dengan persentase kriteria pengetahuan sedang adalah 13 orang (65\%) dan kriteria kurangnya pengetahuan adalah 7 orang $(35 \%)$. Sedangkan persentase setelah diberikan penyuluhan, kriteria pengetahuan yang baik adalah 17 orang $(85 \%)$ dan kriteria sedang adalah 3 orang $(15 \%)$. Hal ini menunjukkan bahwa ada peningkatan pengetahuan penonton yang merupakan ibu rumah tangga antara sebelum dan sesudah diberikan penyuluhan PHBS.

Kata Kunci: perilaku sehat bersih; konseling online; Ibu rumah tangga

\section{Pendahuluan}

Perilaku hidup bersih dan sehat adalah sekumpulan yang dipraktikkan atas dasar kesadaran sebagi hasil pembelajaran yang menjadikan seseorang atau keluarga dapat menolong diri sendiri dan bidang kesehatan dan berperan aktif dalam mewujudkan kesehatan masyarakat. Kondisi sehat dapat dicapai dengan mengubah perilaku dari yang tidak sehat menjadi perilaku sehat dan menciptakan lingkungan sehat di rumah tangga, oleh karena itu kesehatan perlu dijaga, dipelihara dan ditingkatkan oleh setiap anggota rumah tangga serta diperjuangkan oleh semua pihak. Pemerintah Indonesia menjalankan program tersebut untuk menggerakkan pola hidup sehat di kalangan masyarakat, yang dinamakan perilaku hidup bersih dan sehat (Nasution, 2020)

Pencapaian rumah tangga sehat di Indonesia merupakan salah satu indikator rencana strategis Kementrian Kesehatan yang tidak mencapai target ketetapan. Pada tahun 2014, dari target yang telah ditetapkan sebesar $70 \%$ namun hanya dapat dicapai sebesar 56,6\%. Pencapaian tersebut masih belum mencapai target yang telah diharapkan oleh pemerintah (Mahardika, Luthviatin, \& Nafikadini, 2017). Program PHBS pada tatanan rumah tangga merupakan suatu upaya untuk memberdayakan anggota rumah tangga agar tahu, mau dan mampu mempraktikkan perilaku hidup bersih dan sehat serta dapat berperan aktif dalam melakukan gerakan kesehatan di masyarakat (Natsir, 2019)

Kesehatan lingkungan menurut Peraturan Pemerintah nomor 66 tahun 2014 adalah upaya pencegahan penyakit atau gangguan kesehatan dari faktor risiko lingkungan untuk mewujudkan kualitas lingkungan yang sehat dari aspek fisik, kimia, biologi maupun sosial yang diselenggarakan melalui upaya penyehatan, pengamatan dan pengendalian faktor risiko lingkungan (Peraturan Pemerintah Republik, 2014).

Beberapa laporan riset kesehatan sebelumnya diketahui bahwa pada tatanan rumah tangga yang telah menerapkan PHBS baru mencapai 38,7\% yang menunjukkan angka yang masih belum optimal (Rahman \& Patilaiya, 2018). Perilaku Hidup Bersih dan Sehat (PHBS) pada masyarakat Indonesia sebelum menegalami pandemi Covid-19 yaitu masih rendah. PHBS terdiri dari sanitasi yang layak, kebiasaan cuci tangan memakai sabun atau handsanitizer, istirahat yang cukup, kebiasaan tidak merokok, melakukan aktivitas fisik, menkonsumsi makanan sehat,ketersediaan air bersih, dan lain-lain (Jaya, Wulandari, \& Susiloningtyas, 2021). Hal ini tidak hanya memfokuskan pada sumber makan sehat namun juga terkait dengan kebiasaan sehat dalam menjalani 
kehidupan serta tidak kalah penting adalah memiliki pola pikir yang positif (Tontuli, Evert, dkk, 2020)

Berdasarkan data Kementerian Kesehatan Tahun 2019 menunjukkan bahwa sebesar 55\% rumah tangga di Indonesia mempraktikkan PHBS dan 69,27\% rumah tangga memiliki akses terhadap sanitasi layak. Ketika mengalami pandemi Covid-19 terjadi, masyarakat Indonesia memiliki karakteristik sosial beragam, mulai dari, terpapar dari internet/media massa, tingkat pendidikan, status social ekonomi, lingkungan sosial, budaya, suku, kelompok usia, dan lain-lain, mereka memiliki pemahaman dan sikap yang beragam terhadap pandemi Covid-19. Pemahaman dan sikap yang terbentuk ini dapat memengaruhi tindakan/perilaku masyarakat (Jaya et al., 2021). Selain pengetahuan, terdapat faktor lain yang mempengaruhi perilaku hidup bersih dan sehat, yaitu dari faktor sosial ekonomi (Yuliandari, Herya, \& Kunci, 2016).

Dalam penelitian yang dilakukan oleh (Yamaha et al., 2015) didapatkan data bahwa pengetahuan masyarakat tentang PHBS adalah $36.2 \%$ baik, 39,2 \% cukup dan $24,6 \%$ kurang. Hal ini menunjukkan rendahnya pengetahuan mengenai PHBS akan menghambat pelaksanaannya sesuai dengan penelitian yang menyatakan adanya hubungan yang bermakna antara pengetahuan antara pengetahuan dengan kebiasaan cuci tangan sebagai salah satu indikator PHBS. Hal ini juga sesuai dengan penelitian yang dilakukan oleh (Rosidin, Sumarna, \& Eriyani, 2019), bahwa rendahnya PHBS disebabkan karena mayoritas responden memiliki tingkat pengetahuan dalam kategori rendah (Rosidin et al., 2019) . Berdasarkan data diatas, peneliti tertarik untuk mengkaji lebih lanjut tentang pengetahuan ibu rumah tangga mengenai PHBS.

\section{Metode Penelitian}

a. Tahap pra-kerja

Penelitian ini menggunakan metode penelitian kualitatif dengan pendekatan studi kasus deskriptif. Informan penelitian terdiri dari informan yaitu ibu rumah tangga. Teknik purposive digunakan untuk penentuan informan, dimana peneliti menentukan kriteria-kriteria tertentu dalam menentukan informan sebagai data dalam penelitian. Teknik pengumpulan data yang digunakan pada penelitian ini adalah dengan cara wawancara mendalam dan triangulasi sumber. Teknik penyajian data yang digunakan adalah dalam bentuk uraian kata-kata dan kutipan-kutipan langsung dari informan dan dianalisis dengan menggunakan model Miles dan Huberman.Hasil dari wawancara mendalam kepada ibu rumah tangga diperiksa keabsahan datanya.

Pembuatan proposal kegiatan merupakan langkah awal dari kegiatan penyuluhan. Disusul dengan pembuatan materi dalam power point disusun secara lengkap, singkat, padat dan jelas yang disertai gambar untuk menarik perhatian peserta sehingga materi yang disampaikan dapat dipahami oleh peserta. Dilanjutkan dengan menyiapkan link google meet untuk kebutuhan penyuluhan.

b. Tahap pelaksanaan

Setelah audiens masuk dalam google meet sesuai dengan target sasaran, moderator membuka acara, dilanjutkan dengan pemberian sambutan oleh ketua 
panitia, dan sesi pemberian materi mengenai PHBS, setelah sesi pemberian materi berakhir kemuadian dilanjutkan dengan sesi tanya jawab antara pemateri dan audiens.

c. Evaluasi

1. Struktur

Kegiatan penyuluhan dilakukan oleh ibu rumah tangga di wilayah Kota Tangerang sebanyak 20 peserta melalui aplikasi google meet sesuai dengan satuan acara penyuluhan yang telah dibuat.

2. Proses

Kegiatan penyuluhan online dilakukan dari pukul 13.00 s/d 14.30 sesuai dengan jadwal yang telah dibuat dan audiens aktif mengajukan pertanyaan di sesi tanya jawab.

\section{Hasil dan Pembahasan}

Kegiatan penyuluhan dilakukan secara daring dikarenakan kondisi pandemic Covid 19 dimana masih dilakukannya Pembatasan Sosial Berskala Besar (PSBB) di wilayah Kota Tangerang. Sehingga kegiatan penyuluhan yang diadakan pada tanggal 28 Januari 2021 pukul 13.00 s.d 14.30 WIB ini hanya bisa dilakukan melalui media online yaitu google meet, dimana baik panitia maupun audiens mengikuti kegiatan dari rumah masing-masing. Kegiatan penyuluhan ini diikuti oleh 20 orang audiens yang merupakan ibu rumah tangga di sekitar wilayah Kota Tangerang.

Tabel 1

Tingkat Pengetahuan sebelum diberikan penyuluhan PHBS

\begin{tabular}{cccc}
\hline No & Kriteria & N & $\begin{array}{c}\text { Persentase } \\
(\mathbf{\%})\end{array}$ \\
\hline 1 & Baik & & \\
\hline 2 & Sedang & 13 & $65 \%$ \\
\hline 3 & Kurang & 7 & $35 \%$ \\
\hline & Jumlah & 20 & $100 \%$ \\
\hline
\end{tabular}

Tabel 1 menunjukan tingkat pengetahuan ibu rumah tangga mengenai PHBS sebelum diberikan penyuluhan PHBS dengan persentase kriteria sedang 13 orang $(65 \%)$ dan kriteria kurang sebanyak 7 orang (35\%).

Tabel 2

Tingkat Pengetahuan setelah diberikan penyuluhan PHBS

\begin{tabular}{cccc}
\hline No & Kriteria & $\mathbf{N}$ & $\begin{array}{c}\text { Persentase } \\
(\boldsymbol{\%})\end{array}$ \\
\hline 1 & Baik & 17 & $85 \%$ \\
\hline 2 & Sedang & 3 & $15 \%$ \\
\hline 3 & Kurang & 0 & $100 \%$ \\
\hline
\end{tabular}


Tabel 2 menunjukan tingkat pengetahuan ibu rumah tangga setelah diberikan penyuluhan PHBS dengan persentase kriteria baik sebanyak 17 orang $(85 \%)$ dan kriteria sedang sebanyak 3 orang (15\%), data tentang pengetahuan tentang gizi seimbang setelah dilakukan penyuluhan dengan kriteria baik sebanyak 25 peserta $(83,4 \%)$ dan kriteria sedang sebanyak $15(16,6 \%)$.

Tabel diatas, dapat dilihat bahwa adanya peningkatan pengetahuan dari audiens yang merupakan ibu rumah tangga antara sebelum dan sesudah diberikan penyuluhan PHBS. Diharapkan kesadaran mengenai pentingnya perilaku hidup bersih sehat dapat meningkat dan para ibu mampu menjaga, meningkatkan dan melindungi kesehatan setiap anggota rumah tangga dari gangguan ancaman penyakit dan lingkungan.

Penyuluhan perilaku hidup bersih dan sehat yang diberikan kepada audient merupakan bentuk kegiatan yang tidak hanya sekedar memberikan pengetahuan semata, melainkan juga memberikan keterampilan melalui pembimbingan agar dalam rumah tangga dapat menerapkannya secara mandiri dalam kehidupan sehari-hari. Kegiatan ini merupakan bentuk kegiatan pendidikan atau penyuluhan yang secara informal diharapkan dapat mempengaruhi pengetahuan, keterampilan dan sikap/perilaku peserta. Hal ini sesuai dengan pendapat Hamalik (2010) yang menyatakan bahwa pendidikan merupakan suatu usaha yang memiliki tujuan untuk mempengaruhi seseorang dalam menyesuaikan diri dengan lingkungannya, sehingga dapat menimbulkan perubahan dalam dirinya agar dapat berfungsi secara kuat dan nyata dalam kehidupan masyarakat (Zukmadani, Karyadi, \& Kasrina, 2020).

Faktor reinforcing masyarakat dalam menerapkan Perilaku hidup bersih dan sehat dapat berupa dukungan yang diberikan oleh tokoh masyarakat dan budaya untuk mendorong masyarakat untuk melakukan PHBS. Masyarakat sudah mendapat dukungan dari pihak RT dan puskesmas wilayah kerja Kota Tangerang (Gani, Istiaji, \& Pratiwi, 2015).

Pengetahuan merupakan hasil dari "tahu", dan ini terjadi setelah orang melakukan penginderaan terhadap suatu objek tertentu. Selanjutnya, menurut Eni (2012), Perilaku Hidup Bersih dan Sehat (PHBS) merupakan cerminan pola hidup keluarga yang senantiasa memperhatikan dan menjaga kesehatan seluruh anggota keluarga. Semua perilaku kesehatan yang dilakukan atas kesadaran sehingga anggota keluarga dapat menolong dirinya sendiri dibidang kesehatan dan dapat berperan aktif dalam kegiatankegiatan kesehatan dimasyarakat merupakan pengertian lain dari PHBS (Trisnowati \& Daduk, 2017)

Lebih jauh, Proverawati dan Rahmawati (2012) menyatakan bahwa PHBS di Rumah Tangga merupakan upaya untuk memberdayakan anggota rumah tangga agar tahu, mau dan mampu mempraktikkan perilaku hidup bersih dan sehat serta berperan aktif dalam gerakan kesehatan di masyarakat. PHBS di rumah tangga dilakukan untuk mencapai rumah tangga ber PHBS. Rumah tangga yang ber- PHBS adalah rumah tangga yang melakukan 10 PHBS di rumah tangga. Menurut Azwar, (2013), faktorfaktor yang mempengaruhi sikap antara lain: pengalaman pribadi, pengaruh orang lain yang dianggap penting, pengaruh kebudayaan, media massa, lembaga pendidikan dan lembaga agama dan faktor emosional (Trisnowati \& Daduk, 2017) 
Rumah tangga yang menerapkan PHBS berarti mampu menjaga, meningkatkan dan melindungi kesehatan setiap anggota rumah tangga dari gangguan ancaman penyakit dan lingkungan yang kurang konduktif untuk hidup sehat. Penerapan PHBS di rumah tangga, merupakan tanggungjawab setiap anggota rumah tangga, yang juga menjadi tanggung jawab pemerintah/kota beserta jajaran sektor terkait untuk menfasilitasi kegiatan PHBS dirumah tangga agar dapat dijalankan secara efektif. Dengan demikian masyarakat dapat mengenali dan mengatasi masalahnya sendiri, terutama dalam tatanan masing-masing, dan masyarakat dapat menerapkan cara-cara hidup sehat dengan menjaga, memelihara dan meningkatkan kesehatannya (Boekoesoe, Robiyah, \& Yantu, 2016)

Dalam sistem kesehatan nasional (SKN) dikemukakan bahwa masyarakat mempunyai peranan penting dalam memelihara dan meningkatkan diri sendiri dan lingkungan karena Kesehatan merupakan kewajiban dan tanggung jawab setiap orang. Dengan ini mengandung suatu pengertian bahwa dalam penyelenggaraan upaya kesehatan, peran serta masyarakat dinyatakan ikut menentukan keadaan kesehatan baik pada masa sekarang atau masa yang akan datang. Ini berarti setiap orang diharapkan mendukung dan ikut serta dalam menciptakan kehidupan yang sehat. Untuk mencapai keadaan tersebut maka perlu adanya perubahan sikap dan perilaku dari setiap individu selaku warga masyarakat menyangkut bidang kesehatan. Walaupun sebagian masyarakat di daerah penelitian menunjukkan adanya indikasi terjadi perubahan sikap dan perilaku menuju pada kehidupan yang sehat, namun perubahannya belum menyeluruh dan relatif masih banyak yang berperilaku atau menjalankan kebiasaankebiasaan kurang sehat (Karim, 2018)

Dengan dukungan profesi kesehatan merupakan faktor yang dapat mempengaruhi perilaku masyarakat dalam melaksanakan kebiasaan berperilaku hidup bersih dan sehat harus tetap dilakukan. Dukungan mereka dapat mempengaruhi perilaku ibu dengan cara memberikan pendidikan kesehatan tentang pengertian, indikator terkait, dan bahaya jika tidak mengamalkan kebiasaan berperilaku hidup besih dan sehat. Upaya yang harus dilakukan adalah promosi Kesehatan program PHBS dengan tiga strategi pokok, yaitu pemberdayaan, bina suasana dan advokasi. Pemberdayaan yang dilakukan dengan memposisikan masyarakat agar memiliki peran yang besar dalam pengambilan keputusan dan penetapan tindakan yang berkaitan dengan kesehatannya, melalui pemberian informasi secara terus menerus dan berkesinambungan mengikuti perkembangan sasaran serta proses membantu sasaran agar terjadi perubahan. Diskusi partisipatif yaitu dengan penyampaian informasi Kesehatan bukan hanya searah tetapi dilakukan secara partisipatif. Hal ini berarti masyarakat bukan hanya menerima yang pasif tapi juga ikut aktif berpartisipasi di dalam diskusi tentang informasi yang diterimanya (Karim, 2018) 


\section{Kesimpulan}

PHBS adalah upaya memberikan pengalaman belajar bagi perorangan, keluarga, kelompok, dan masyarakat dengan membuka jalur komunikasi, memberikan informasi dan edukasi guna meningkatkan pengetahuan, sikap dan perilaku melalui pendekatan advokasi, bina suasana dan gerakan masyarakat sehingga dapat menerapkan cara-cara hidup sehat dalam rangka menjaga, memelihara, dan meningkatkan kesehatan masyarakat. Tingkat pengetahuan ibu rumah tangga mengenai PHBS sebelum diberikan penyuluhan PHBS dengan persentase kriteria pengetahuan sedang 13 orang $(65 \%)$ dan kriteria pengetahuan kurang sebanyak 7 orang $(35 \%)$. Sedangkan persentase setelah diberikan penyuluhan, kriteria pengetahuan baik sebanyak 17 orang $(85 \%)$ dan kriteria sedang sebanyak 3 orang (15\%). Hal ini menunjukkan bahwa adanya peningkatan pengetahuan dari audiens yang merupakan ibu rumah tangga antara sebelum dan sesudah diberikan penyuluhan PHBS. Dengan diadakannya kegiatan penyuluhan di tatanan rumah tangga diharapkan kesadaran mengenai pentingnya perilaku hidup bersih dan sehat dapat meningkat dimulai dari rumah sendiri dan dapat di kembangkan pada lingkungan sekitar. 


\section{BIBLIOGRAFI}

Boekoesoe, Lintje, Robiyah, Rahayu, \& Yantu, Veybe M. (2016). Dan Status Ekonomi Masyarakat Clean and Healthy Life Behavior in Household Arrangements Reviewed From the Aspect of Knowledge and Status of. 241-257.Google Scholar

Gani, Husni Abdul, Istiaji, Erdi, \& Pratiwi, Prita Eka. (2015). Perilaku Hidup Bersih dan Sehat (PHBS) Pada Tatanan Rumah Tangga Masyarakat Using (Studi Kualitatif di Desa Kemiren, Kecamatan Glagah, Kabupaten Banyuwangi) A Qualitative Study in Kemiren Village, Glagah Sub District, Banyuwangi Regency. Jurnal IKESMA, 11(1), 26-35.Google Scholar

Jaya, Susanti Tria, Wulandari, Ratna Feti, \& Susiloningtyas, Luluk. (2021). Pendidikan Kesehatan PHBS Kader Kesehatan Era New Normal di Desa Darungan. Journal of Community Engagement in Health, 4(1), 162-166.Google Scholar

Karim, Dedi Sempurna Putra. (2018). Determinan Perilaku Hidup Bersih dan Sehat (PHBS) Tatanan Rumah Tangga. Jurnal Ilmu Kesehatan Masyarakat, 7(01), 19. Google Scholar

Mahardika, Nurike Hanani, Luthviatin, Novia, \& Nafikadini, Iken. (2017). Tindakan Ibu Rumah Tangga dalam Penerapan Indikator PHBS Tidak Merokok di dalam Rumah ( Studi Kualitatif di Wilayah Kerja Puskesmas Pasirian)( The Housewife Behavior in the Implementation Indicators PHBS No Smoking in The House ( a Qualitative Study in . 5(3).Google Scholar

Nasution, Ade Saputra. (2020). Edukasi PHBS di Tatanan Rumah Tangga Untuk Meningkatkan Perilaku Sehat. Jurnal Abdidas, 1(2), 28-32. Google Scholar

Natsir, Muh. Fajaruddin. (2019). Perilaku Hidup Bersih Dan Sehat (PHBS) Pada Tatanan Rumah Tangga Masyarakat Desa Parang Baddo. Jurnal Nasional Ilmu Kesehatan ( JNIK ), 1(3), 54-59. Google Scholar

Peraturan Pemerintah Republik. (2014). Peraturan Pemerintah Republik. Https://Jdih.Kemenkeu.Go.Id/FullText/2014/66TAHUN2014PP.

Rahman, Hamidah, \& Patilaiya, Hairudin La. (2018). Pemberdayaan Masyarakat Melalui Penyuluhan Perilaku Hidup Bersih dan Sehat untuk Meningkatkan Kualitas Kesehatan Masyarakat. JPPM (Jurnal Pengabdian Dan Pemberdayaan Masyarakat), 2(2), 251. Google Scholar

Rosidin, Udin, Sumarna, Umar, \& Eriyani, Theresia. (2019). Determinan Pelaksanaan PHBS Rumah Tangga di Desa Jayaraga Tarogong Kidul Kabupaten Garut. Jurnal Keperawatan BSI, 7(1). Google Scholar

Trisnowati, Heni, \& Daduk, Stefandri Suryatno. (2017). Karangnongko Yogyakarta. 12, 1-11. Google Scholar 
Yamaha, Sponsorship terhadap niat beli motor, Bpr, P. T., memediasi, peran sikap pada iklan dalam, pendingin, hijau, di denpasar, udara merek 1. g., harga, epsdanpe, likuiditas, ukuran, food, modal perusahaan, \& indonesia, bursa efek. (2015). Peran emosi positif sebagai pemediasi pengaruh stimulus toko terhadap impulse buying pakaian di matahari department store kuta square. E-Jurnal Manajemen Universitas Udayana, 4(3). Google Scholar

Yuliandari, Dwi Wahyu, Herya, Nurnaningsih, \& Kunci, Kata. (2016). Pengaruh Pengetahuan Dan Sosial Ekonomi Keluarga Terhadap Penerapan Perilaku Hidup Bersih Dan Sehat (Phbs) Tatanan Rumah Tangga Di Wilayah Kerja Puskesmas X Kota Kediri Relationship of Knowledge and Socio-Economic of Family With Clean and Healthy Behaviou. 17-22. Google Scholar

Zukmadani, Alif Yanuar, Karyadi, Bhakti, \& Kasrina. (2020). Edukasi Perilaku Hidup Bersih dan Sehat (PHBS) dalam Pencegahan COVID-19 Kepada Anak-Anak di Panti Asuhan. Jurnal Pengabdian Masyarakat, 3(1), 68-76.

\section{Copyright holder :}

Liana Oktariani, Isna Dewi Aulia dan Ria Setia Sari Jasmin (2021)

First publication right :

Journal Syntax Idea

This article is licensed under:

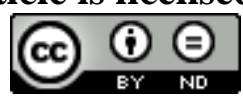

